\section{SpyBite-assisted biliary cannulation for intradiverticular papilla during ERCP}

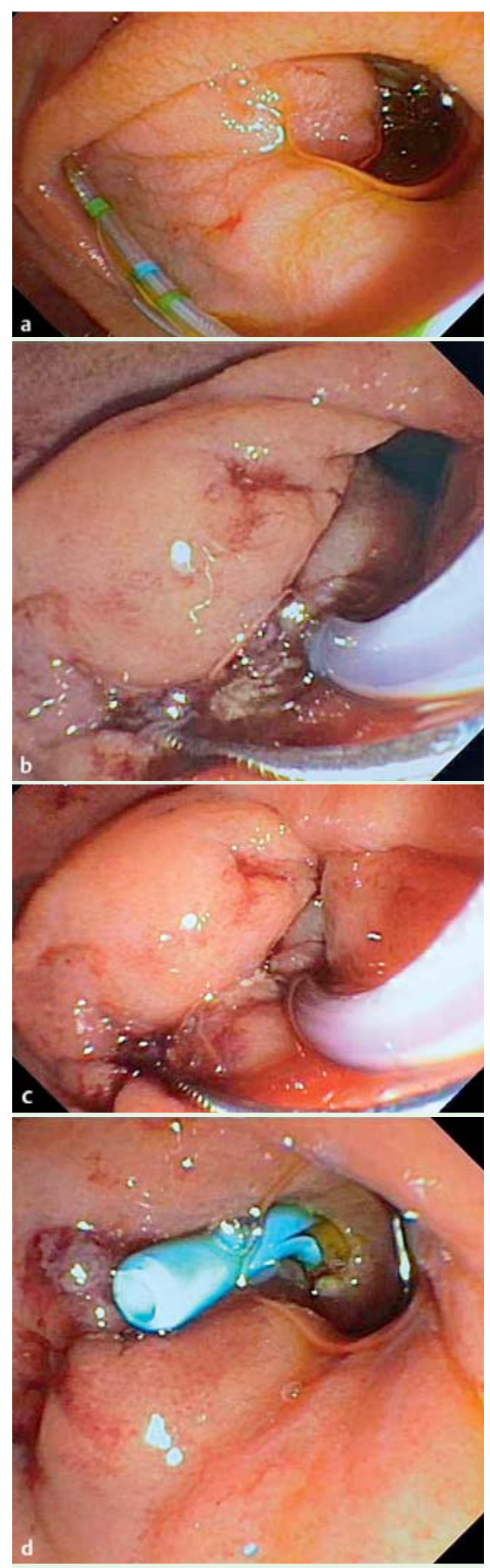

Fig. 1 Endoscopic views showing: a the papilla, which is visible only after the diverticula edge and redundant tissue have been retracted; b SpyBite-assisted cannulation being performed with a dual instrument technique using a single channel; $\boldsymbol{c}$ the SpyBite forceps reducing the redundant tissue and the sphincterotome in the duct during cannulation; $\mathbf{d}$ the stent protruding from the orifice of the common bile duct.
Periampullary diverticula are common, occurring in up to $20 \%$ of patients undergoing endoscopic retrograde cholangiopancreatography (ERCP) [1,2]. A subset of these patients has a true intradiverticular papilla (IDP), which can make biliary cannulation more challenging. Several techniques to facilitate common bile duct (CBD) cannulation have been described in case reports and series, including a double-wire endoclip-assisted technique [3], and endoscopic ultrasound (EUS)-guided or percutaneous-guided rendezvous techniques [4]. Here we report a single case that demonstrates a technique that has been used at our institution on multiple patients with difficult to cannulate IDPs using SpyBite forceps (Boston Scientific, Natick, Massachusetts, USA) to change the anatomic positioning of the papilla to gain access.

A 67-year-old man on his eighth postoperative day following an open cholecystectomy was found to have a bile leak. After an ERCP failed because of the inability to locate the ampulla caused by a large duodenal diverticulum, the patient was referred to our facility for an attempted repeat ERCP and stent placement. On duodenoscopy, the papilla could only be visualized with eversion of redundant diverticular tissue using the sphincterotome $(\circlearrowleft$ Fig. 1 a). Once mechanical traction was released, the papilla resumed its previously inaccessible position inside the edge of the diverticulum.

Mechanical traction and attempted fixation of the redundant tissue to facilitate access to the papilla using both Instinct endoscopic hemoclips (Cook Medical, Bloomington, Indiana, USA) and Resolution clips (Boston Scientific) were unsuccessful. The use of pediatric forceps (Olympus) through the channel with the CleverCut3 sphincterotome (Olympus) was also unsuccessful. Subsequently, a SpyBite forceps was passed through the channel with the sphincterotome. The SpyBite forceps was opened and used to grasp the redundant duodenal tissue and push the mucosa to the side, so exposing the ampulla. It easily reduced the redundant tissue and allowed for successful biliary cannulation ( $\bullet$ Fig. 1 b, c), followed by stent placement $(\boldsymbol{O}$ Fig. $\mathbf{1}$ d).

When confronted with a difficult CBD cannulation because of an IDP, we recommend considering the use of the SpyBite forceps to help reduce the redundant tissue, maintain the ampullary position, and improve access.

\section{Endoscopy_UCTN_Code_TTT_1AR_2AB}

\section{Competing interests: None}

\section{John M. Levenick, Timothy B. Gardner, Zilla H. Hussain, Stuart R. Gordon}

Section of Gastroenterology and Hepatology, Dartmouth-Hitchcock Medical Center, Lebanon, New Hampshire, USA

\section{References}

1 Parlak E, Koksal AS, Disebeyaz S et al. Additional biliary cannulation methods in patients with juxtapapillary duodenal diverticula. Dig Dis Sci 2012; 57: 2982 -2987

2 Lobo DN, Balfour TW, Iftizkhar SY. Periampullary diverticula: consequences of failed ERCP. Ann R Coll Surg Engl 1998; 80: 326 331

3 Huang CH, Tsou YK, Lin CH et al. ERCP for intradiverticular papilla: endoclip-assisted biliary cannulation. Endoscopy 2010; 42: E223-E224

4 Lai R, Freeman ML. Endoscopic ultrasoundguided bile duct access for rendezvous ERCP drainage in the setting of intradiverticular papilla. Endoscopy 2005; 37: 487-489

\section{Bibliography}

Dol http://dx.doi.org/

10.1055/s-0034-1377365

Endoscopy 2014; 46: E514

(c) Georg Thieme Verlag KG

Stuttgart · New York

ISSN 0013-726X

\section{Corresponding author}

\section{John M. Levenick, MD}

Section of Gastroenterology and Hepatology

Dartmouth-Hitchcock Medical Center

One Medical Center Drive

Lebanon

NH 03756

USA

Fax: +1-603-650-5225

john.m.levenick@hitchcock.org 